\title{
Immunological evaluation of the crevicular fluid in patients with gingivitis, periodontitis, and peri-implantitis: a 1-year cross-sectional study
}

\author{
Avaliação imunológica do fluido crevicular em pacientes com gengivite, periodontite e peri- \\ implantite: um estudo transversal de 1 ano \\ Evaluación inmunológica del líquido crevicular en pacientes con gingivitis, periodontitis y \\ periimplantitis: un estudio transversal de 1 año
}

Received: 09/17/2021 | Reviewed: 09/27/2021 | Accept: 10/02/2021| Published: 10/04/2021

Juliana Barbosa de Faria

ORCID: https://orcid.org/0000-0002-9681-2278 Federal University of Triangulo Mineiro, Brazil

E-mail: julibfaria@hotmail.com

Taíssa Cássia de Souza Furtado ORCID: https://orcid.org/0000-0002-8186-1798

University of São Paulo, Brazil

E-mail: taissacassia@hotmail.com

Thaís Soares Farnesi de Assunção ORCID: https://orcid.org/0000-0003-3415-9004 University of Federal Triangulo Mineiro, Brazil E-mail: thais.assuncao@uftm.edu.br

Douglas Reis Abdalla

ORCID: https://orcid.org/0000-0002-6971-1201

Centro Universitário UniBrasilia, Brazil

E-mail: profdouglasabdalla@gmail.com

Fabiane Minin Andrade

ORCID: https://orcid.org/0000-0002-6156-3988

University of Uberaba, Brazil

E-mail: fabianeminin@gmail.com

Bárbara Bellocchio Bertoldo

ORCID: https://orcid.org/0000-0003-0628-9792

Federal University of Triangulo Mineiro, Brazil

E-mail: barbarabellocchiob@hotmail.com

Eleonora de Paula Amaral

ORCID: https://orcid.org/0000-0002-3107-2002 University of Uberaba, Brazil

E-mail: eleonoramaral@yahoo.com

Denise Bertulucci Rocha Rodrigues ORCID: https://orcid.org/0000-0003-4003-542X University of Uberaba, Brazil Federal University of Triangulo Mineiro, Brazil E-mail: denise.rodrigues@uniube.br

Virmondes Rodrigues Júnior ORCID: https://orcid.org/0000-0001-8706-4223 Federal University of Triangulo Mineiro, Brazil

E-mail: virmondes.rodrigues@uftm.edu.br

Sanivia Aparecida de Lima Pereira ORCID: https://orcid.org/0000-0002-0293-2587 University of Uberaba, Brazil Federal University of Triangulo Mineiro, Brazil

E-mail: sanivia.pereira@uniube.br

\begin{abstract}
Objective: To assess the levels of IL-12, IL-15, IL-18, and IL-32 in the gingival crevicular fluid (GCF) and periimplant crevicular fluid (PICF) in patients with gingivitis, periodontitis, and peri-implantitis before and one year after implant installation. Material and Methods: Forty-nine samples of GCF and PICF were collected from March 2018 to March 2019. The patients were classified: patients with gingivitis $(n=7)$, patients with periodontitis $(n=14)$, patients with peri-implantitis $(n=4)$ and healthy patients $(n=24)$. The crevicular fluid from the 49 patients was collected before implant installation $(n=8)$ and one year after implant placement $(n=8)$. The Enzyme-Linked Immunosorbent Assay (ELISA) was used to evaluate the levels of cytokines in crevicular fluid. Results: Patients with gingivitis,
\end{abstract}


periodontitis, and peri-implantitis showed higher concentrations of IL-12, IL-15, IL-18, and IL-32 when compared with control group. In general, the levels of IL-12 and IL-15 increased when compared to the moments before and after implant installation. There was also an increase in the concentration of IL-18 in the control group volunteers after implant installation. Conclusion: The results and methodology of this study showed that there was no difference in the synthesis of IL-12, IL-15, IL-18, and IL-32 in healthy individuals or in those with periodontal injuries. However, there was an increase in the cytokines IL-12, IL-15, and IL-18 one year after implant installation, which would be increasing the inflammatory activity in peri-implantitis.

Keywords: Cytokines; Periodontal diseases; Gingival crevicular fluid; Peri-implantitis.

\section{Resumo}

Objetivo: Avaliar os níveis de IL-12, IL-15, IL-18 e IL-32 no fluido crevicular gengival (FCG) e peri-implantar (FCPI) de pacientes com gengivite, periodontite e peri-implantite antes e um ano após a instalação do implante. Material e Métodos: Quarenta e nove amostras de FCG e FCPI foram coletadas entre março de 2018 a março de 2019. Os pacientes foram classificados de acordo com a situação periodontal ou peri-implantar: pacientes com gengivite $(n=7)$, pacientes com periodontite $(n=14)$, pacientes com peri-implantite $(n=4)$ e pacientes saudáveis $(n=24)$. Desses 49 pacientes, foi coletado fluido crevicular antes da instalação do implante $(n=8)$ e um ano após a instalação do implante $(n=8)$. O Ensaio de Imunoabsorção Enzimática (ELISA) foi usado para avaliar os níveis de citocinas no fluido crevicular. Resultados: Pacientes com gengivite, periodontite e peri-implantite apresentaram maiores concentrações de IL-12, IL-15, IL-18 e IL-32 quando comparados ao grupo controle. Em geral, os níveis de IL-12 e IL-15 aumentaram quando comparados aos momentos antes e após a instalação do implante. Também houve aumento na concentração de IL-18 nos voluntários do grupo controle após a instalação do implante. Conclusão: Os resultados e a metodologia deste estudo mostraram que não houve diferença na síntese de IL-12, IL-15, IL-18 e IL-32 em indivíduos saudáveis ou com lesão periodontal. Porém, houve aumento das citocinas IL-12, IL-15 e IL-18 um ano após a instalação do implante, o que estaria aumentando a atividade inflamatória na peri-implantite.

Palavras-chave: Citocinas; Doenças periodontais; Líquido do sulco gengival; Peri-implantite.

\section{Resumen}

Objetivo: Evaluar los niveles de IL-12, IL-15, IL-18 e IL-32 en el líquido crevicular gingival (LCG) y en el líquido crevicular periimplantar (LCP) de pacientes con gingivitis, periodontitis y periimplantitis antes y un año después de la colocación del implante. Material y métodos: Se recogieron 49 muestras de FCG y FCPI entre marzo de 2018 y marzo de 2019. Los pacientes se clasificaron según el estado periodontal o periimplantario: pacientes con gingivitis ( $\mathrm{n}=7$ ), pacientes con periodontitis $(n=14)$, pacientes con periimplantitis $(n=4)$ y pacientes sanos $(n=24)$. De estos 49 pacientes, se recogió líquido crevicular antes de la instalación del implante $(n=8)$ y un año después de la instalación del implante $(n=8)$. Se utilizó un ensayo inmunoenzimático (ELISA) para evaluar los niveles de citoquinas en el líquido crevicular. Resultados: Los pacientes con gingivitis, periodontitis y periimplantitis presentaban mayores concentraciones de IL-12, IL-15, IL-18 e IL-32 en comparación con el grupo de control. En general, los niveles de IL12 e IL-15 aumentaron en comparación con los momentos anteriores y posteriores a la instalación del implante. También se produjo un aumento de la concentración de IL-18 en los voluntarios del grupo de control tras la instalación del implante. Conclusión: Los resultados y la metodología de este estudio mostraron que no había diferencias en la síntesis de IL-12, IL-15, IL-18 e IL-32 en sujetos sanos o en sujetos con lesiones periodontales. Sin embargo, hubo un aumento de las citocinas IL-12, IL-15 e IL-18 un año después de la instalación del implante, lo que aumentaría la actividad inflamatoria en la periimplantitis.

Palabras clave: Citoquinas; Enfermedades periodontales; Líquido del surco gingival; Periimplantitis.

\section{Introduction}

Periodontal diseases are inflammatory processes that start in the gingiva as a response to bacterial antigens that accumulate on the dental plaque throughout the gingival margin. The plaque is a biofilm formed by bacteria, salivary proteins, and desquamated epithelial cells. Bacteria trigger the production of cytokines and chemokines on the gingival epithelium, leading to the expression of adherence molecules and to the increase of the permeability of gingival capillaries and of the chemotaxes of neutrophils through the junctional epithelium into the gingival sulcus (Silva et al., 2015). The earlier manifestation of the periodontal disease is gingivitis, which is characterized by hyperemia, edema, and gingival bleeding. When gingivitis is not treated early, it can evolve into a periodontitis, which is characterized by the loss of the insertion of the periodontal tissue that gives support and protection to the dental element. Therefore, the periodontitis affects deeper structures, causing the resorption of the collagen fibers of the periodontal ligament, the resorption of the alveolar bone, abscesses, increase of the gingival sulcus depth, greater tooth mobility, and loss of the dental element (Zhang et al., 2020). 
The progression of the periodontal disease does not depend only on the bacteria, but also on the immunological response. Consequently, the immune response of the host has an essential role in the balance between the destruction and the recovery of the periodontal tissue. Therefore, current researches about periodontal diseases have focused on the immunological responses involved in them (Zhang et al., 2020).

On the other hand, the bacteria in the biofilm can also provoke revertible inflammation on the mucosa that surrounds dental implants (peri-implant mucositis) and irreversible injuries in the tissue that sustains these implants (peri-implantitis) (Rinke et al., 2020). This can trigger marginal bleeding, mobility, and loss of the implanted dental element, compromising both aesthetic and function. Similarly to periodontal diseases, the cytokines released in the site contribute for the progress of these diseases (Ali et al., 2021). However, these peri-implant diseases are still not fully understood. So far there is no consensus on the etiologies and pathogenesis, especially when compared to periodontitis (Kalsi, Moreno, \& Petridis, 2021).

However, the installation of dental implants brings great benefits to patients and has contributed to reducing the number of edentulous patients worldwide. The treatment of edentulism with dental implants is a routine treatment in daily dental practice and is becoming more and more widespread over the years (Kormas et al., 2020). Although there has been a great advance in the area of these implants in recent years, the number of failures related to inflammation of the peri-implant tissue has also increased. Currently, the prevalence of periimplant diseases is high, with $43 \%$ progressing to periimplant mucositis and $22 \%$ progressing to periimplantitis (Rinke et al., 2020).

The number of studies in this area is growing in order to understand the immunological mechanism involved in the progression of these diseases, since the assessment of inflammatory cytokine levels in periodontal and peri-implant diseases can allow the identification of the active disease, contributing to the diagnosis and early treatment (Ali et al., 2021).

The present study was carried out aiming to contribute for the understanding of tissue injury in gingivitis, periodontitis, and peri-implantitis, starting from the principle that interleukins (IL) and other cytokines stimulate cells from several different lineages and differentiation stages.

Figure 1 summarizes the behavior of the immune response during the establishment and development of the periodontal lesion. During gingivitis and, later, periodontitis, immune cells, such as TCD4+ lymphocytes and NK cells are activated and produce IFN- $\gamma$, a key cytokine for other interleukins to be activated, such as IL-12, IL-15, IL-18, and IL-32 (Zhuang et al., 2018). Once these cytokines are produced, a feedback loop is activated, more IFN- $\gamma$ is produced and more NK cells are activated, creating a serious inflammatory disorder (Pradeep et al., 2009). This disorder is characterized by high levels of IL-12, IL-15, IL-18, IL-32, which are proinflammatory cytokines, related to the liberation of other proinflammatory cytokines (IFN- $\gamma$ and TNF- $\alpha$ ) (Nakanish et al., 2001) and chemokines. This group of cytokines (Interleukins 12, 15, 18, and 32) have proteolytic action, thus acting in the progression of inflammatory diseases such as gingivitis and periodontitis (Conti, Youinou, \& Theoharides, 2007). 
Figure 1 - Relation between IL-12, IL-15, IL-18, and IL-32.

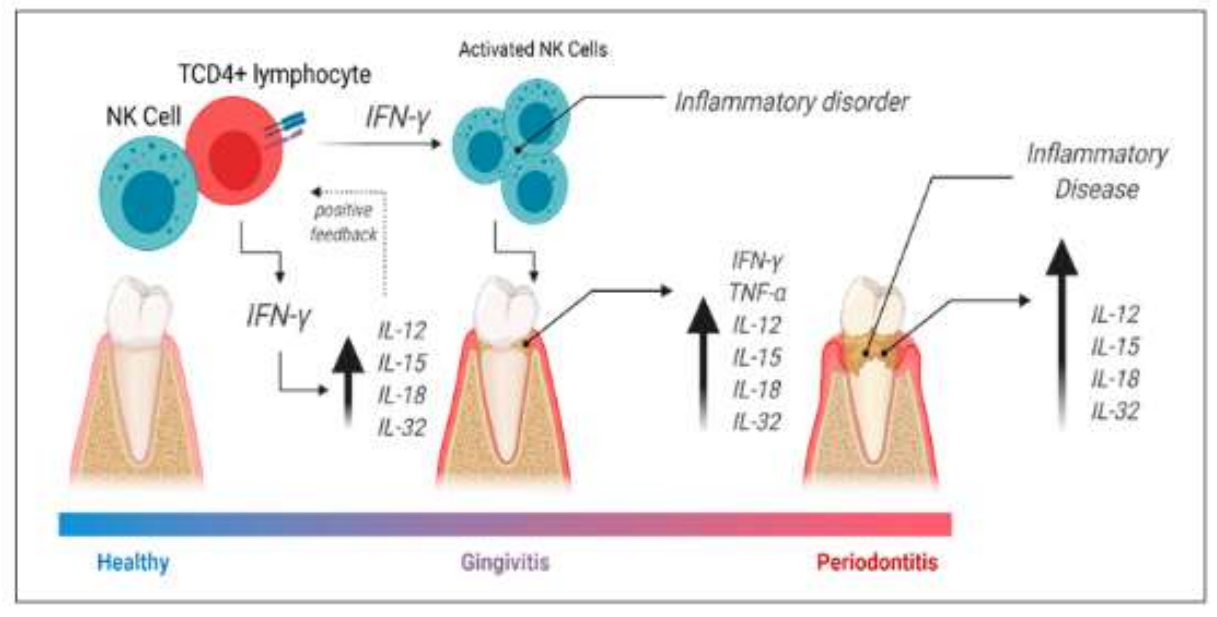

Created by BioRender.com. Source: Authors (2021).

Although there are studies that evaluated the immune response in periodontal and peri-implant tissues (Ali et al., 2021), this is the first study to simultaneously compare the levels of IL-12, IL-15, IL-18 and IL-32 in the crevicular fluid from patients with gingivitis, periodontitis and periimplantitis. Also, the first study to compare all these cytokines simultaneously, before and one year after the installation of dental implants.

As all the immunological mechanisms involved in these diseases are not yet understood, the results of the present study will allow us to bring new knowledge for better understanding of the pathogenesis of periodontal and peri-implant diseases. This study can contribute to a better quality of life for people, since the understanding of the mechanisms of these diseases can collaborate in the adoption of prophylactic and therapeutic measures in order to prevent the loss of teeth and dental implants. Knowing the importance of teeth for aesthetic, mastication, and phonetics is enough to justify the need to understand the pathogenesis of these diseases.

Therefore, the objective of this study was to evaluate the levels of IL-12, IL-15, IL-18, and IL-32 in the gingival fluids of patients with gingivitis, periodontitis, and peri-implantitis, before the extraction of the teeth and one year after the placement of dental implants.

\section{Methodology}

\section{Selection of patients}

This prospective cross-sectional study was approved by the Ethics Committee on Human Research of the University of Uberaba/MG, Brazil, under protocol number 2.457.394, CAAE: 64947717.0.0000.51. All eligible patients were informed about the nature of the study and about the potential risks and benefits of participating by signing the Informed Consent Form. The clinical investigation was carried out according to the principles from the Declaration of Helsinki. The patients were selected during the peri-implant support therapy, from March 2018 to March 2019, in the Getúlio Vargas Polyclinic from the University of Uberaba/MG, in Uberaba, Minas Gerais, Brazil. Medical and odontological information were obtained from the patients, who agreed participating in the study and were in accordance with the inclusion/exclusion criteria.

Forty-nine patients were selected and classified according to their periodontal situation: patients with gingivitis ( $\mathrm{n}=7$ ), patients with periodontitis $(n=14)$, patients with peri-implantitis $(n=4)$, and healthy patients $(n=24)$. The crevicular fluid from the 49 patients was collected before $(n=8)$ and one year the placement of the implant $(n=8)$. In this group $(n=8)$ the patients 
were classified according to their periodontal situation: patients with gingivitis $(n=4)$, patients with periodontitis $(n=3)$, patients with peri-implantitis $(\mathrm{n}=1)$.

For the selection criteria of teeth and implant for collection, the tooth and implant with the greatest probing depth were selected. Importantly, all patients in the study received implants and most patients had more than one implant in their oral cavity. When a patient had periodontitis or peri-implantitis in more than one site, the one with the greatest probing depth was selected.

The inclusion criteria for the selection of patients were: 1. Healthy patients: absence of gingival erythema, bleeding on probing, edema, suppuration, and no increase in probing depth when compared to previous exams (Berglundh et al., 2018). Furthermore, the patients had to be in a good general state of health, not having para-functional habits, and sign the Free and Informed Consent Form; 2. Patients with gingivitis: probing depths of up to $3 \mathrm{~mm}, 10 \%$ or more places with bleeding on probing, no clinical attachment loss or radiographic bone loss (Chapple et al., 2018); 3. Patients with periodontitis: clinical attachment loss detected in one or more interproximal non-adjacent sites or loss of insertion of $3 \mathrm{~mm}$ or more in the vestibule or lingual/palate in at least two teeth, as long as not caused by: a) traumatic gingival recession; b) dental cavity reaching the cervical area of the teeth; c) loss of insertion in the distal surface of a second molar and associated to the bad position or extraction of a third molar; d) endoperiodontal lesion draining through the marginal periodontium or e) vertical root fracture (Tonetti, Greenwell, \& Kornman, 2018; Papapanou et al., 2018); 4. Patients with peri-implantitis: a) signs of peri-implant inflammation (gingival erythema, bleeding at probing, edema, suppuration, and increase in probing depth when compared to previous exams), b) radiographic evidence of bone loss after initial healing, and c) radiographic bone level $\geq 3 \mathrm{~mm}$ accompanied by bleeding at probing and probing depth $\geq 6 \mathrm{~mm}$ (Renvert et al., 2018).

The exclusion criteria to select the patients were: prior periodontal or peri-implant therapy for at least one year, relevant systemic diseases not-compensated for, such as diabetes and osteoporosis; the use of antibiotics or anti-inflammatory in the last six months; smoking; chronic alcoholics; pregnant women; implants with mobility or suppuration, and those who did not accept signing the Consent Form (De Araújo et al., 2017).

The following parameters were evaluated in six sites of each implant (mesial-vestibular, vestibular, disto-vestibular, mesial-lingual, lingual, and disto-lingual), using a periodontal probe (PCPUNC-15BR Hu-Friedy, São Paulo, Brazil): (a) marginal bleeding - the presence or absence of bleeding was recorded by passing of the periodontal probe alongside the margins of the soft tissue; (b) suppuration - presence or absence of suppuration, spontaneous or when probing; (c) probing depth - distance in millimeters from the margin of the mucosa to the bottom of the sulcus or the peri-implant pocket (De Mendonça et al., 2009).

\section{Collection of peri-implant and gingival fluid}

For the collection of gingival and peri-implant fluid, selected teeth or implants were isolated using sterile gauze and the collection places were softly dried with an air syringe. Four absorbent paper points number 40 were placed, isolated, in each place of collection (mesial-vestibular, vestibular, disto-vestibular, mesial-lingual, lingual, disto-lingual), for approximately $2 \mathrm{~mm}$ in the sulcus/pocket for 30 seconds each. Points contaminated by blood or saliva were discarded. Later, the points were placed in an epperndorf tube with a 0.5 Phosphate-Buffered Saline (PBS) buffer solution, pH 7.2, composed by $1.9 \mathrm{~g}$ monobasic potassium phosphate $\left(\mathrm{KH}_{2} \mathrm{PO} 4\right), 5.1 \mathrm{~g}$ sodium phosphate $\left(\mathrm{Na}_{2} \mathrm{HPO} 4\right), 42.5 \mathrm{~g}$ sodium chloride $(\mathrm{NaCl})$, and 500 $\mathrm{ml}$ ultrapure water, distilled in a Milli Q ${ }^{\circledR}$ (Millipore) device and frozen at $-70^{\circ} \mathrm{C}$ (Escobar et al., 2018). 
Quantification of IL-12, IL-15, IL-18, and IL-32 in the gingival crevicular fluid (GCF) and the peri-implant crevicular fluid (PICF)

The samples collected were analyzed through an enzyme-linked immunosorbent assay (ELISA) to determine the levels of IL-12, IL-15, IL-18, and IL-32 using specific antibody pairs commercially available, according to the recommendations of the manufacturer (Quantikine, R\&D Systems, Minneapolis, MN, EUA). The following kits from R\&D Systems were used: a) Human IL-12 p70 Quantikine ELISA Kit - listing number: D1200; b) Human IL-15 Quantikine ELISA Kit - listing number: D1500; c) Human Total IL-18 DuoSet ELISA - listing number: DY318-05; d) Human IL-32 DuoSet ELISA - listing number: DY3040-05. High-sensitivity 96 well flat bottom plates (Microplate, PS, half area, high binding, Greiner Bio-One GmbH, Frickenhausen, Germany). Later, they were cleaned using PBS/Tween $0.05 \%$ in an automated cleaner, blocked with $150 \mu \mathrm{l}$ of PBS/BSA $1 \%$ (at least one hour, room temperature) and cleaned again using PBS/Tween $0.05 \%$. The samples were added to the wells of the plates and, in parallel, a standard curve was incorporated through serial dilutions of the respective recombinant cytokine. The samples throughout the curve were incubated through night at $4^{\circ} \mathrm{C}$. The wells were then cleaned using PBS/Tween $0.05 \%$ and, later, $50 \mu 1 /$ well were inserted with their respective detection antibodies. They remained for three hours in room temperature and were later cleaned using the PBS/Tween $0.05 \%$. After this stage, 50 $\mu \mathrm{L} /$ well of alkaline phosphatase were pipetted with streptavidin in PBS/BSA 1\%, remaining in room temperature and protected from direct light for two hours. Later, the plates were cleaned using PBS/Tween $0.05 \%$, after which $50 \mu 1 /$ well of the substrate solution were added. The reaction was interrupted using a $2 \mathrm{~N}$ of $\mathrm{H}_{2} \mathrm{SO} 4$ solution. The results were found using absorbance measures of $450 \mathrm{~nm}$ and $570 \mathrm{~nm}$ in an automated ELISA reader (Enspire, Perkin Elmer, EUA). The concentrations of the mediators were determined using a linear regression with the absorbance values found in the curves and expressed in $\mathrm{pg} / \mathrm{mL}$. The results were calculated using standard curves created in each assay, and the absorbance was found comparing the difference between the first and the second wavelengths (R\&D SYSTEMS, 2020). The ELISA assay was blind.

\section{Quantification of total proteins (TPs)}

The concentration of cytokines indicated by the automated ELISA reader (Enspire, Perkin Elmer, USA) was corrected according with the total concentration of total proteins (TPs) in the crevicular fluid. To do so, $2 \mu \mathrm{L}$ of the sample of crevicular fluid were analyzed in a Spectrophotometer NanoDrop® 2000 (Thermo Fisher Scientific, Wilmingtong, DE, EUA). The samples were considered adequately pure when the ratio between absorbances, for 230nm (Green \& Sambrook, 2018).

\section{Statistical Analysis}

The statistical analysis was carried out using Excel 2013 for Windows (Microsoft - EUA), GraphPad Prism, version 8. The Shapiro-Wilk Test was used to verify the normal distribution of the quantitative variables. The continuous variables, which present normal distribution, were expressed in mean \pm standard deviation. For the multiple comparisons, the ANOVA test and Tukey's test were used. Student's t-test was used for single comparisons. Variables that did not have normal distribution were expressed in median, minimum, and maximum. For the multiple comparisons, the Kruskal-Wallis and Dunn's tests were used. For single comparisons, Mann-Whitney's test was used. The significance level assumed for the variables was $5 \%(\alpha=0.05)$.

\section{Results}

The concentration of cytokine dosages between control voluntaries and those affected by gingivitis, periodontitis, and peri-implantitis can be seen in table 1 . There were no statistically significant differences regarding the concentrations of IL-12 
( $p=0.5222)$, IL-15 $(p=0.8463)$, IL-18 $(p=0.9980)$, and IL-32 $(p=0.4039)$ between the control volunteers and those affected by gingivitis, periodontitis, or peri-implantitis (Table 1).

Table 1 - Representation of the dosage of cytokine in control group patients and those with gingivitis, periodontitis, and periimplantitis.

\begin{tabular}{lcccc}
\hline & $\begin{array}{c}\mathrm{IL}^{2}-12^{\mathrm{a}} \\
(\mathrm{n}=49)\end{array}$ & $\begin{array}{c}\text { IL-15 } \\
(\mathrm{n}=49)\end{array}$ & $\begin{array}{c}\text { IL-18 } \\
(\mathrm{n}=49)\end{array}$ & $\begin{array}{c}\text { IL-32 }^{\mathrm{d}} \\
(\mathrm{n}=49)\end{array}$ \\
\hline Control & $23.7(2.7-363.5)$ & $34.1(5.7-263.5)$ & $24.6(4.0-213.5)$ & $12.2(0.0-711.6)$ \\
Gingivitis & $19.8(7.3-57.4)$ & $30.3(9.0-60.0)$ & $22.5(19.0-39.7)$ & $7.3(0.0-73.7)$ \\
Periodontitis & $38.9(5.4-97.1)$ & $39.1(8.0-75.7)$ & $26.6(3.7-51.79)$ & $0.0(0.0-124.8)$ \\
Peri-Implantitis & $17.0(12.9-46.3)$ & $24.2(20.3-48.4)$ & $24.1(17.1-33.5)$ & $7.0(0.0-136.8)$ \\
\hline
\end{tabular}

${ }^{a}$ Kruskal-Wallis test with $p=0.5222$;

b Kruskal-Wallis test with $p=0.8463$;

${ }^{\mathrm{c}}$ Kruskal-Wallis test with $p=0.9980$;

${ }^{\mathrm{d}}$ Kruskal-Wallis test with $p=0.4039$.

Source: Authors (2021).

Figure 2 is a residual representation of the dosage of interleukins, to show that the concentrations of cytokines IL-12, IL-15, and IL-18 were higher in the crevicular fluid of the group with periodontitis, when compared to the other groups.

Figure 2 - Heat map representation of cytokines IL-12, IL-15, IL-18 E IL-32, comparing the experimental group volunteers $(n=49)$.

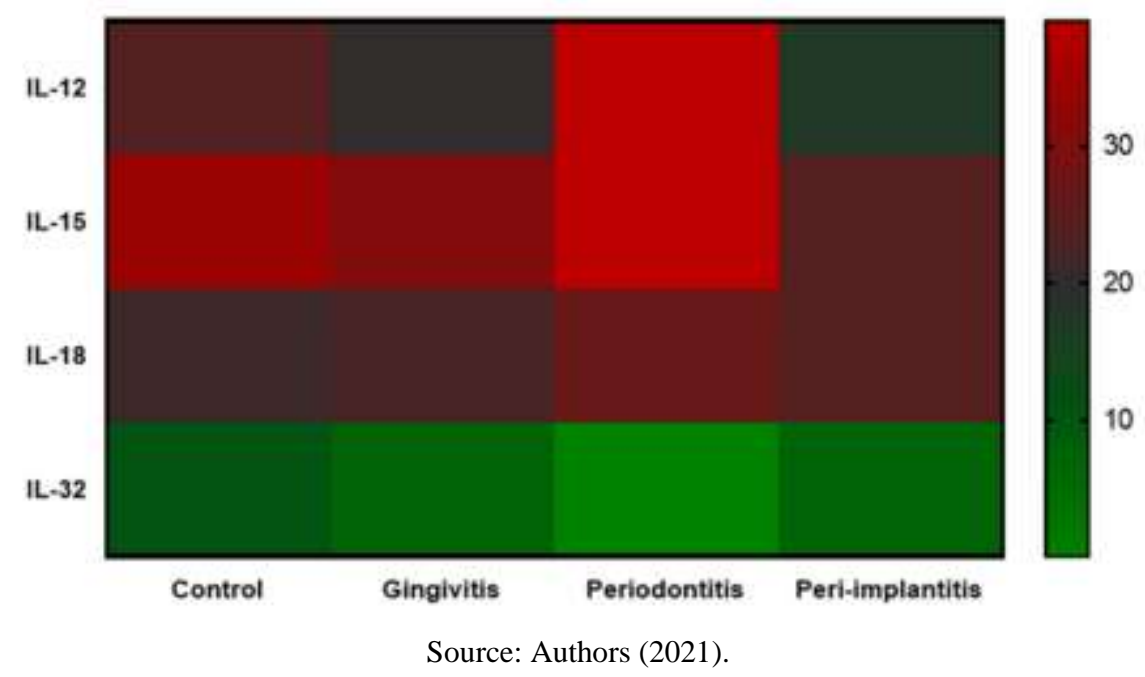

Regarding the expression of cytokines IL-12, IL-15, IL-18, and IL-32 between volunteers who received implants, figure 3 shows the analysis of the moments before the implant and one year after the implant. The levels of IL-12 ( $p=0.0499)$ and IL-15 ( $p=0.0011)$ increased after the implant, as shown in images 3A and 3B, respectively. The concentrations of IL-18 $(p=0.08)$ also increased when the moment before the implant was compared with one year later (Figure 3C), there was no statistically significant difference. Finally, the IL-32 were lower after one year of the implant, albeit with no statistical difference (Figure 3D). 
Figure 3 - Representation of the dosages of cytokines comparing the moments before and after the implant. ${ }^{\text {a Mann }}$ Whitney, IL-12: $p=0,0499$; ${ }^{\mathrm{b}}$ Mann Whitney, IL-15: $p=0,0011$; ${ }^{\mathrm{c}}$ Mann Whitney, IL-18: $p=0,08$; ${ }^{\mathrm{d}}$ Mann Whitney, IL-32: $p=1$; (n=8)

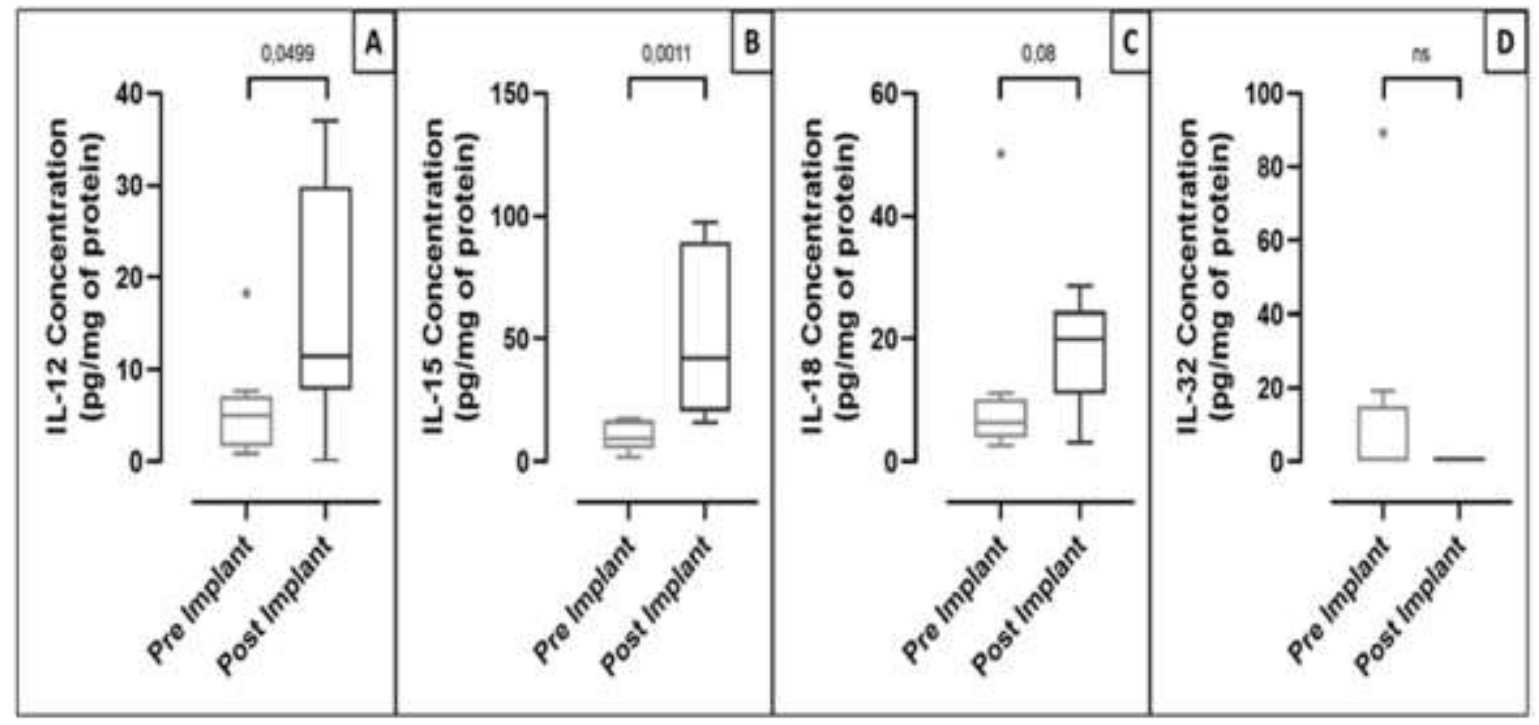

Source: Authors (2021).

Figure 4A shows the cytokines IL-12, IL-15, IL-18, and IL-32 before and after the implant, between control volunteers and those with periodontal injuries (gingivitis and/or periodontitis). Regarding the IL-12 dosages, in Figure 4A, this cytokine increased after the implant, both for control volunteers and for volunteers with periodontal injuries. However, this result was not statistically significant. The dosages of IL-15 (Figure 4B) increased after the implant in both groups. However, in the control group, this increase trended towards a statistically significant result $(p=0.0512)$, while in the group with periodontal injuries there was a significant increase in IL-15 concentration $(p=0.0407)$. Finally, there was also an increase in the IL-18 concentration ( $p=0.0153$ ) among control volunteers, when the moments before and after the implant were compared (Figure 4C).

Figure 4 - Representation of the dosages of cytokines, comparing moments before and after the implant, between control volunteers and those with injuries (gingivitis and/or periodontitis). ${ }^{b}$ Kruskal-Wallis test and Dunn's post test, IL-15: $p=0.0512$ before implant control vs. after implant control; ${ }^{\mathrm{b}}$ Kruskal-Wallis test and Dunn's post test, IL-15: $p=0.0407$ before implant lesion vs. after implant lesion; 'Kruskal-Wallis test and Dunn's post test, IL-18: $p=0.0153$ before implant control vs. after implant control; $(n=8)$.

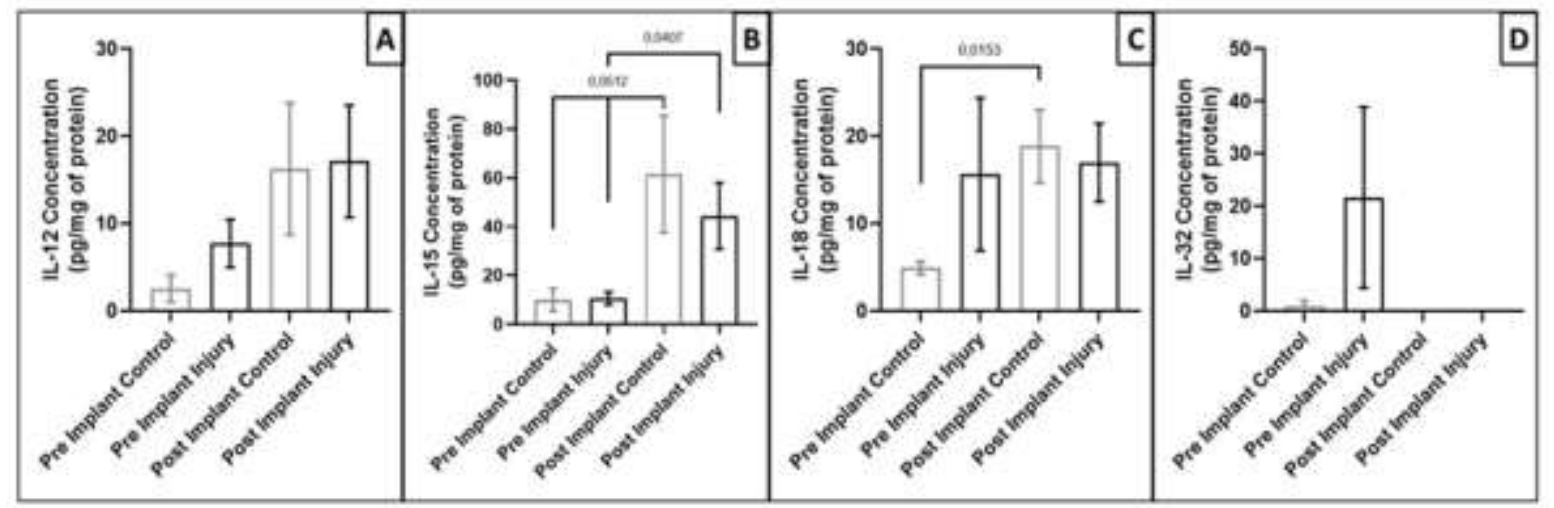

Source: Authors (2021). 
Regarding Figure 5, it is a residual representation of cytokine concentrations. It is possible to notice that there was an increase in the concentration of the IL-12, IL-15, and IL-18 cytokines when we compare the moments before the implant in control volunteers and in those with injuries (gingivitis and/or periodontitis). There was also an increase in the concentration of cytokines IL-12 and IL-15, when the moment after the implant is compared between control volunteers and those with injuries (gingivitis and/or periodontitis) (Figure 5).

Figure 5 - Heat map representation of cytokines IL-12, IL-15, IL-12, and IL-32, comparing moments before and after the implant, between control volunteers and those with injuries (gingivitis and/or periodontitis) $(n=8)$.

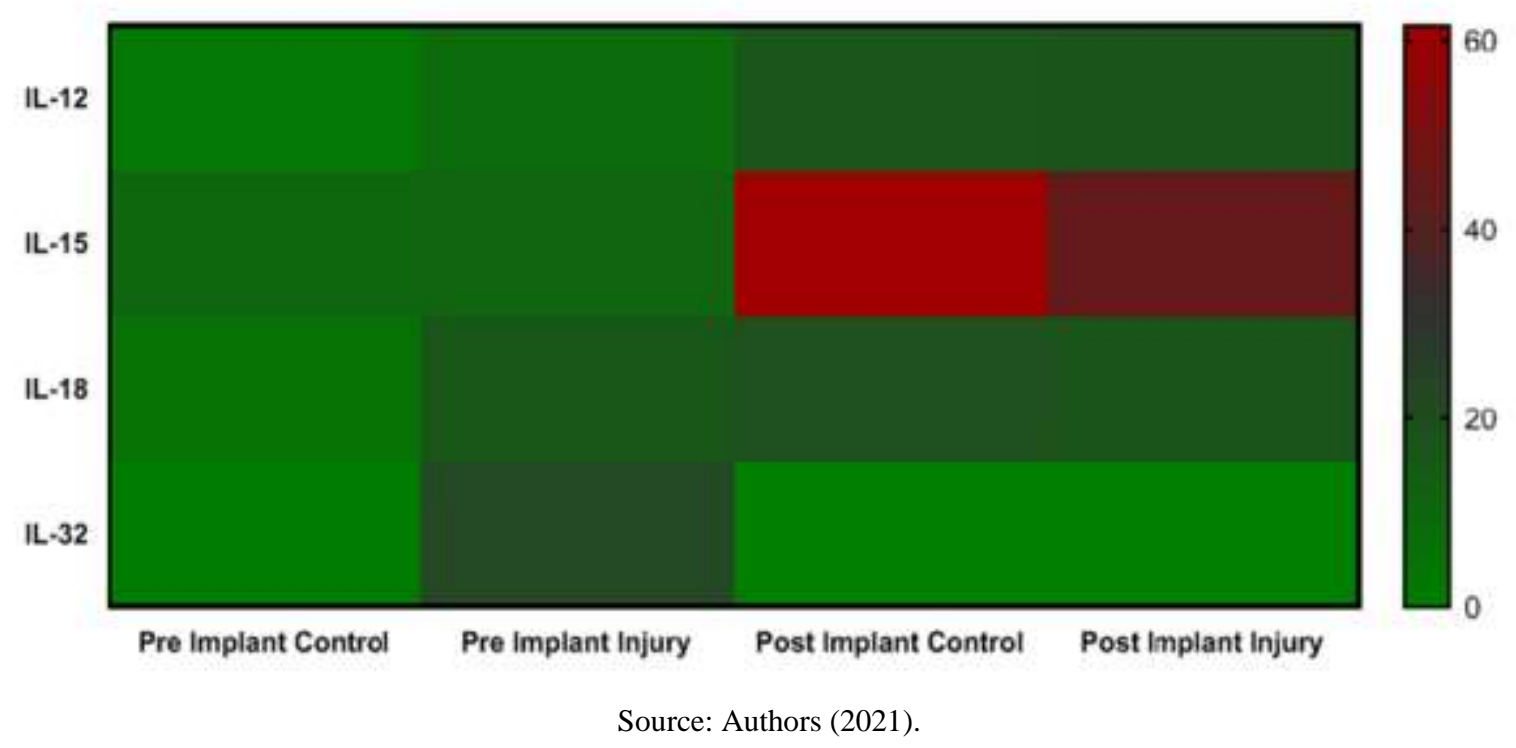

\section{Discussion}

The null hypothesis was not rejected in this study, since there was no significant difference between the cytokines analyzed in the control group and the groups with gingivitis, periodontitis, and peri-implantitis. Regarding the analysis of the cytokines before and after the implant, the null hypothesis was rejected for cytokines IL-12, IL-15, IL-18, because a significant difference was observed.

We evaluated the patients one year after they had an implant placed, since the functional load can collaborate for marginal bone loss around the implants. ${ }^{41}$ According to the literature consulted, this is the first study that simultaneously compared the levels of IL-12, IL-15, IL-18, and IL-32 in the gingival crevicular fluid (GCF) of patients with gingivitis and periodontitis, in addition to the peri-implant crevicular fluid (PICF) in peri-implantitis, using the ELISA method.

Our study did not observe statistically significant differences regarding IL-12, IL-15, IL-18, and IL-32 concentrations between control volunteers and those affected by gingivitis, periodontitis, and peri-implantitis, corroborating a previous study in which the authors showed that the profile of proinflammatory cytokines (TNF- $\alpha$, IL1- $\beta$, TGF- $\beta 2$ ) in the periodontal tissue, measured by the method ELISA, was similar to the peri-implant tissue at three different points in time (0, 21, 90 days) after the placement of the implant (Schierano et al., 2008). A previous study found, opposed to these findings, that IL-12 and IL-18 induced severe inflammatory disturbance, suggesting that IL-18 is a potent proinflammatory cytokine with a physiopathological role in many inflammatory conditions (Pradeep et al., 2009). Furthermore, IL-32 is known to be secreted by several cells after the stimulation of some inflammatory cytokines, such as Il-12, IL-1b, IFN- $\gamma$, IL-18. The IL-32 is an inflammatory cytokine produced by lymphocytes, epithelial cells activated by IFN- $\gamma$, NK cells (Goda et al., 2006). 
Furthermore, the IL-32 acts over macrophages/monocytes, encouraging the synthesis of TNF- $\alpha$ and IL-6, as well as inducing the secretion of chemokines (IL-8 and MIP-2), being important in the triggering and persistence of the inflammatory process (Kim et al., 2005). Still regarding IL-32, this cytokine antagonizes the activation of NK cells to inhibit phosphorylation of STAT5 mediated by IL-15, suppressing its expression of an effector molecule induced by IL-15, with cytolytic capacity (Gorvel et al., 2017). IL-15, in turn, controls the liberation of IL-18 by human monocytes, creating a proinflammatory environment, as induced by IFN- $\gamma$ (Sattler et al., 2015). The combination of IL-15 and IL-18 could induce the expression of IFN- $\gamma$ and granzyme B, suggesting that when these cytokines act together, they are more potent (Ussher et al., 2013). Interleukins IL-15 and IL-32 contributed together to cause physiopathological events that include cell death, inflammation, allergy, and epithelial cell autoimmunity (Conti, Youinou, \& Theoharides, 2007). Although the human recombinant IL-32 induces the production of many proinflammatory cytokines and chemokines (Conti, Youinou, \& Theoharides, 2007), our study suggests that IL-32 may have contributed for the non-activation of IL-12, IL-15, IL-18, inhibiting the levels of these cytokines in the gingival crevicular fluid (GCF) and in the peri-implant crevicular fluid (PICF).

Cytokines IL-12, IL-15, and IL-18 presented higher levels in the group with periodontitis when compared to the other groups. Furthermore, after the implant, there was an increase in the concentration of cytokines IL-12, IL-15, and IL-18 when compared to the moment one year after the implant, for both the control and injured patients. This can be made clear by the fact that the human NK cells show an adaptive behavior in response to a combination of proinflammatory cytokines, such as interleukins IL-12, IL-15, and IL-18. (Romee et al., 2016). All cytokines mentioned lead to the generation of NK cells with functional "memory" properties (Zhuang et al., 2018). It has been shown that the cell line of monocytes and macrophages can respond to the encouragement of IL-15, increasing Il-18 and IL-12 (Bannwart et al., 2007). Furthermore, the IL-18 is a cytokine responsible for the beginning and progression of the periodontal disease (Figueredo et al., 2008). Therefore, the periodontal inflammation may not be resolved successfully due to the accumulation of IL-18. A previous study showed that levels of IL-18 in GCF increased in places where there was periodontitis, suggesting that this cytokine is associated to the severity of the periodontal disease (Orozco et al., 2006). The same thing was verified in the previous study in which the IL-18 had an extremely important role in gingival inflammation and a strong expression of IL-18 was found in gingival samples with the increase of the sulcus depth (Johnson \& Serio, 2005). Therefore, in our study, we suggest that this combination of IL12/15/18 cytokines has the same function in the generation of NK cells. Furthermore, the activity of IL-18 often requires costimulating factors to respond, such as IL-12 or IL-15, which is why we believe that IL-18 may have interfered in the results of patients with periodontal diseases.

The levels of IL-12 and IL-15 increased after the implant. Regarding the IL-12 dosages, this cytokine increased after the implant, both for control volunteers and for volunteers with periodontal injuries. However, this result was not statistically significant. The IL-15 dosages, comparing the moments before and after implant, increased for both groups. However, it also trended towards a significant increase in the control group. There was also an increase in the concentration of cytokines IL-12 and IL-15 when we compare the moment after the installation of the implant, comparing control volunteers and those who had injuries (gingivitis and/or periodontitis). The combination of IL-15 and IL-12 contributes for the production of IFN- $\gamma$, TNF- $\alpha$, and GM-CSF by human NK cells (Carson et al., 1995). Additionally, the synergy between IL-12 and IL-15 is responsible for inducing the response of Th1 cells against infections by intracellular microorganisms (Yoshikai \& Nishimura, 2000). Therefore, both IL-15 and IL-12, produced by activated human monocytes, had a critical role as cofactors in the production of IFN- $\gamma$ by NK cells, which is important to activate monocytes and for the development of an effective innate immune response for infections, before the appearance of antigen-specific T cell responses (Carson \& Caligiuri, 1998). As a result, we suggest that cytokines IL-12 and IL-15, which contribute for the production of IFN- $\gamma$, could be the key for the generation of NK cells, 
which are important components of innate bacteria immunity, acting in the development of inflammations due to their quick response and to their intimate relation with the production of proinflammatory cytokines, leading to peri-implantitis.

There was a significant increase in IL-15 in the group with periodontal injuries. These results corroborate the previous study, according to which the total amount of IL-15 in the GCF of the group with gingivitis was significantly higher when compared to the healthy controls (Buduneli et al., 2003). Since the IL-15 is a proteolytic proinflammatory cytokine, it is superexpressed in several inflammatory diseases such as gingivitis and peri-implantitis. The proinflammatory cytokine IL-15 is more present in tissue injuries and in the fluids of chronic inflammatory diseases (Conti, Youinou, \& Theoharides, 2007). Furthermore, an in vitro study showed that IL-15 induced the expression of monocyte chemotactic protein-1 (MCP-1) by peripheral blood monocytes. The authors found that IL-15, produced in inflammation sites, may play an essential role in the regulation of blood leukocytes (Badolato et al., 1997). Our findings suggest that IL-15, since it is a proinflammatory cytokine, may be pronounced in tissue injuries and in the fluids of chronic inflammatory diseases, justifying its superexpression in our studies in the groups with gingivitis and periodontitis.

No statistically significant difference was found regarding the concentrations of IL-18, although the cytokine increased after the implant. The results corroborate another study which showed a gradual increase in the concentration of IL18 in the peri-implant crevicular fluid after 3 months of functioning (Hu et al., 2019). The IL-18 increased one year after the implant was placed, since it is a proinflammatory cytokine that can induce IFN- $\gamma$, GM-CSF, TNF- $\alpha$, and IL- 1 in immunocompetent cells, which can activate cell death by lymphocytes and regulate the expression of certain chemokine receptors (Nakanishi et al., 2001). As a result, we believe that the increase in IL-18 one year after the implant was placed is associated to an intensified proinflammatory activity, indicating local inflammation, which suggests peri-implantitis.

Although the levels of IL-32 were lower one year after the implant, this diminution was not significant, and it is known that human recombinant IL-32 induces the production of several proinflammatory cytokines and chemokines (Conti, Youinou, \& Theoharides, 2007). This cytokine is produced mainly by T lymphocytes, NK cells (Novick et al., 2006) and by dendritic cells, when stimulated by IL-15 (Gorvel et al., 2017). Furthermore, IL-32 is secreted by several cells after the stimulation of certain inflammatory cytokines, such as IL-12, IL-1b, IFN- $\gamma$, IL-18 (Goda et al., 2006). IL-32 acts on macrophages/monocytes, stimulating the synthesis of TNF- $\alpha$ and IL-6, inducing the secretion of chemokines (IL-8, MIP-2). As mentioned above, although the IL-32 induces the production of several proinflammatory cytokines (Conti, Youinou, \& Theoharides, 2007) and is important in the triggering and persistence of the inflammatory process (Kim et al., 2005), although in our study suggests that the suppression of IL-32 interfered with the results. In addition, no studies were found in literature that related IL-32 to peri-implantitis.

Considering this, it is essential to trace an immune response profile that compares periodontal diseases and periimplantitis, since it is known that patients with periodontal diseases are more likely to develop peri-implant diseases (Sgolastra et al., 2013).

This study had limitations, once we obtained a reduced number of samples, as it was not possible to collect samples from all patients one year after implants installation. This study evaluated the local immune responses of gingivitis, periimplantitis, and periodontitis in two moments: before and after the implant was placed. As a result, there was a prospective evaluation one year after the placement of the implant.

\section{Conclusion}

According to the results and methodology of this study, there was no difference in the synthesis of IL-12, IL-15, IL18 , and IL-32 in healthy individuals or in those with periodontal injuries. However, there was an increase in the cytokines IL12, IL-15, and IL-18 one year after the implant was placed, which would be increasing the inflammatory activity in peri- 
implantitis. Since this was the first study to correlate the cytokines IL-12, IL-15, IL-18, and IL-32 before placement of an implant and one year after it, in the volunteers of a control group and in those with injuries (gingivitis and/or periodontitis), more studies would be necessary to better understand the immunological balance in gingivitis, periodontitis, and periimplantitis.

In summation, local factors, functional implants, and the time since the installation of the implant must be considered for future studies, so that base cytokine levels in in the peri-implant crevicular fluid can be verified.

\section{Declaration of human rights}

All procedures carried out in studies involving human beings were in accordance with the ethical standards of the institutional and/or national research committees and with the 1964 Declaration of Helsinki and with its later amendments or with comparable ethical standards.

\section{Acknowledgments}

We would like to thank the professors and students from the Universidade de Uberaba who gave us support. To the coordinator of the Post-graduation Implantology Course, Alan Garcia Essado and to the Coordinator of the Dentistry course, and Luís Henrique Borges, professors at the Universidade de Uberaba (UNIUBE) for providing their authorization and help in the collection of samples from the Getúlio Vargas Polyclinic, in the Universidade de Uberaba (UNIUBE). We also thank Dr. Marcos Vinícius da Silva and Dr. Ana Carolina de Morais Oliveira, for collaborating by performing the Enzyme-Linked Immunosorbent Assay (ELISA), carried out in the immunology laboratory at the Universidade Federal do Triângulo Mineiro (UFTM). This work was financed by the Post-graduation Program in Health Sciences from the Universidade Federal do Triângulo Mineiro (UFTM), by the Coordenação de Aperfeiçoamento de Pessoal de Nível Superior (CAPES); by the Postgraduation Program in Dentistry and the Scientific Initiation Program from the Universidade de Uberaba (PIBIC-UNIUBE2019/004); by the Cefores/Universidade Federal do Triângulo Mineiro (UFTM); by the Conselho Nacional de Desenvolvimento Científico e Tecnológico (CNPq-PQ-2018/Process No. 302867/2018-0), and by the Fundação de Amparo à Pesquisa de Minas Gerais (FAPEMIG). The funding sources were not involved in the design of the study, data collection, analysis, writing, nor in the decision to submit the paper for publication.

\section{Declarations of interest}

The authors declare no conflicts of interest.

\section{References}

Ali, M., Yang, F., Plachokova, A. S., Jansen, J. A., \& Walboomers, X. F. (2021). Application of specialized pro-resolving mediators in periodontitis and peri-implantitis: a review. European Journal of Oral Sciences, 129(1). 10.1111/eos.12759

Badolato, R; Ponzi, A.N.; Millesimo, M., Notarangelo, L. D., \& Musso, T. Interleukin-15 (IL-15) induces IL-8 and monocyte chemotactic protein 1 production in human monocytes. Blood. 1997;90(7):2804-2809. https://0019-9567/98/\$04.0010

Bannwart, C. F., Nakaira, E. T., Sartori, A., \& Peraçoli, M. T. S. (2007). Interleukin-15: its role in microbial infections. Journal of Venomous Animals and Toxins Including Tropical Diseases, 13(3). 10.1590/s1678-91992007000300002

Berglundh, T., Armitage, G., Araujo, M. G., Avila-Ortiz, G., Blanco, J., Camargo, P. M., \& Zitzmann, N. (2018). Peri-implant diseases and conditions: Consensus report of workgroup 4 of the 2017 World Workshop on the Classification of Periodontal and Peri-Implant Diseases and Conditions. Journal of Clinical Periodontology, 45, S286-S291. 10.1111/jcpe.12957

Buduneli, E., Genel, F., Atilla, G., \& Kütükçüçler, N. (2003). Evaluation of p53, bcl-2, and Interleukin-15 Levels in Gingival Crevicular Fluid of Cyclosporin A-Treated Patients. Journal of Periodontology, 74(4), 506-511. 10.1902/jop.2003.74.4.506 
Carson, W., \& Caligiuri, M. A. (1998). Interleukin-15 as a potential regulator of the innate immune response. Brazilian Journal of Medical and Biological Research, 31(1), 1-9. 10.1590/s0100-879x1998000100001

Carson, W.E., Ross, M. E., Baiocchi, R. A., Marien, M.J., Boiani, N,, Grabstein, K; Caligiuri, M. A. (1995). Endogenous production of interleukin 15 by activated human monocytes is critical for optimal production of interferon-gamma by natural killer cells in vitro. The Journal of Clinical Investigation. 96 , 2578-82. 10.1172/JCI118321

Chapple, I. L. C., Mealey, B. L., Van Dyke, T. E., Bartold, P. M., Dommisch, H., Eickholz, P., \& Yoshie, H. (2018). Periodontal health and gingival diseases and conditions on an intact and a reduced periodontium: Consensus report of workgroup 1 of the 2017 World Workshop on the Classification of Periodontal and Peri-Implant Diseases and Conditions. Journal of Clinical Periodontology, 45, S68-S77. 10.1111/jcpe.12940

Conti, P., Youinou, P., \& Theoharides, T. C. (2007). Modulation of autoimmunity by the latest interleukins (with special emphasis on IL-32). Autoimmunity Reviews, 6(3), 131-137. 10.1016/j.autrev.2006.08.015

De Araújo, M. F., Etchebehere, R. M., de Melo, M. L. R., Beghini, M., Severino, V. O., de Castro Côbo, E., \& de Lima Pereira, S. A. (2017). Analysis of CD15, CD57 and HIF-1 $\alpha$ in biopsies of patients with peri-implantitis. Pathology - Research and Practice, 213(9), 1097-1101. 10.1016/j.prp.2017.07.020

De Mendonça, A. C., Santos, V. R., César-Neto, J. B., \& Duarte, P. M. (2009). Tumor Necrosis Factor-Alpha Levels After Surgical Anti-Infective Mechanical Therapy for Peri-Implantitis: A 12-Month Follow-Up. Journal of Periodontology, 80(4), 693-699. 10.1902/jop.2009.080521

Escobar, G. F., Abdalla, D. R., Beghini, M., Gotti, V. B., Junior, V. R., Napimoga, M. H.; Ribeiro, B. M., Rodrigues, D. B. R.; Nogueira, R. D., \& de Lima Pereira, S.A. (2018). Levels of Pro and Anti-inflammatory Citokynes and C-Reactive Protein in Patients with Chronic Periodontitis Submitted to Nonsurgical Periodontal Treatment. Asian Pacific Journal of Cancer Prevention, 19(7), 1927-1933. 10.22034/APJCP.2018.19.7.1927

Figueredo, C. M., Rescala, B., Teles, R. P., Teles, F. P., Fischer, R. G., Haffajee, A. D., \& Gustafsson, A. (2008). Increased interleukin-18 in gingival crevicular fluid from periodontitis patients. Oral Microbiology and Immunology, 23(2), 173-176. 10.1111/j.1399-302x.2007.00408.x

Goda, C., Kanaji, T., Kanaji, S., Tanaka, G., Arima, K., Ohno, S., \& Izuhara, K. (2006). Involvement of IL-32 in activation-induced cell death in T cells. International Immunology, 18(2), 233-240. 10.1093/intimm/dxh339

Gorvel, L., Korenfeld, D., Tung, T., \& Klechevsky, E. (2017). Dendritic Cell-Derived IL-32 $\alpha$ : A Novel Inhibitory Cytokine of NK Cell Function. The Journal of Immunology, 199(4), 1290-1300. 10.4049/jimmunol.1601477

Green, M. R., \& Sambrook, J. (2018). A Single-Step Method for the Simultaneous Preparation of DNA, RNA, and Protein from Cells and Tissues. Cold Spring Harbor Protocols. 2018(1), pdb.prot093500. 10.1101/pdb.prot093500

Hu, Z., Wu, D., Zhao, Y., Chen, S., \& Li, Y. (2019). Inflammatory cytokine profiles in the crevicular fluid around clinical healthy dental implants compared to the healthy contralateral side during the early stages of implant function. Archives of Oral Biology, 104509. 10.1016/j.archoralbio.2019.10

Johnson, R. B., \& Serio, F. G. (2005). Interleukin-18 Concentrations and the Pathogenesis of Periodontal Disease. Journal of Periodontology, 76(5), 785790. 10.1902/jop.2005.76.5.785

Kalsi A., Moreno, F., \& Petridis, H. (2021). Biomarkers associated with periodontitis and peri-implantitis: a systematic review. Journal of Periodontal \& Implant Science, 51(1): 3-17. 10.5051/jpis.1902840142

Kim, S.-H., Han, S.-Y., Azam, T., Yoon, D.-Y., \& Dinarello, C. A. (2005). Interleukin-32. Immunity, 22(1), 131-142. 10.1016/j.immuni.2004.12.003

Kormas, I., Pedercini, C., Pedercini, A., Raptopoulos, M., Alassy, H., \& Wolff, L.F. (2020). Peri-Implant Diseases: Diagnosis, Clinical, Histological, Microbiological Characteristics and Treatment Strategies. A Narrative Review. Antibiotics. 9(11), 835. 10.3390/antibiotics9110835

Nakanishi, K., Yoshimoto, T., Tsutsui, H., \& Okamura, H. (2001). Interleukin-18 regulates both Th1 and Th2 responses. Annual Review of Immunology, 19(1), 423-474. 10.1146/annurev.immunol.19.1.

Novick, D., Rubinstein, M., Azam, T., Rabinkov, A., Dinarello, C. A., \& Kim, S.-H. (2006). Proteinase 3 is an IL-32 binding protein. Proceedings of the National Academy of Sciences, 103(9), 3316-3321. 10.1073/pnas.0511206103

Orozco, A., Gemmell, E., Bickel, M., \& Seymour, G. J. (2006). Interleukin-1 beta, interleukin-12 and interleukin-18 levels in gingival fluid and serum of patients with gingivitis and periodontitis. Oral Microbiology and Immunology, 21(4), 256-260. 10.1111/j.1399-302x.2006.00292.x

Papapanou, P. N., Sanz, M., Buduneli, N., Dietrich, T., Feres, M., Fine, D. H., \& Tonetti, M. S. (2018). Periodontitis: Consensus report of workgroup 2 of the 2017 World Workshop on the Classification of Periodontal and Peri-Implant Diseases and Conditions. Journal of Clinical Periodontology, 45, S162S170. 10.1111/jcpe. 12946

Pradeep, A. R., Daisy, H., Hadge, P., Garg, G., \& Thorat, M. (2009). Correlation of Gingival Crevicular Fluid Interleukin-18 and Monocyte Chemoattractant Protein-1 Levels in Periodontal Health and Disease. Journal of Periodontology, 80(9), 1454-1461. 10.1902/jop.2009.090117

Renvert, S., Persson, G. R., Pirih, F. Q., \& Camargo, P. M. (2018). Peri-implant health, peri-implant mucositis, and peri-implantitis: Case definitions and diagnostic considerations. Journal of Clinical Periodontology, 45, S278-S285. 10.1111/jcpe.12956

Rinke, S., Nordlohne, M., Leha, A., Renvert, S., Schmalz, G., \& Ziebolz, D. (2020). Risk indicators for mucositis and peri-implantitis: results from a practicebased cross-sectional study. Journal of Periodontal \& Implant Science, 50(3), 183-196. 10.5051/jpis.2020.50.3.183

Romee, R., Rosario, M., Berrien-Elliott, M. M., Wagner, J. A., Jewell, B. A., Schappe, T., \& Fehniger, T. A. (2016). Cytokine-induced memory-like natural killer cells exhibit enhanced responses against myeloid leukemia. Science Translational Medicine, 8(357), 357ra123-357ra123. 10.1126/scitranslmed.aaf2341 
Research, Society and Development, v. 10, n. 13, e41101320756, 2021

(CC BY 4.0) | ISSN 2525-3409 | DOI: http://dx.doi.org/10.33448/rsd-v10i13.20756

Sattler, A., Dang-Heine, C., Reinke, P., \& Babel, N. (2015). IL-15 dependent induction of IL-18 secretion as a feedback mechanism controlling human MAITcell effector functions. European Journal of Immunology, 45(8), 2286-2298. 10.1002/eji.201445313

Schierano, G., Pejrone, G., Brusco, P., Trombetta, A., Martinasso, G., Preti, G., \& Canuto, R. A. (2008). TNF- $\alpha$ TGF- $\beta 2$ and IL-1 $\beta$ levels in gingival and periimplant crevicular fluid before and after de novo plaque accumulation. Journal of Clinical Periodontology, 35(6), 532-538. 10.1111/j.1600051x.2008.01224.x

Sgolastra, F., Petrucci, A., Severino, M., Gatto, R., \& Monaco, A. (2013). Periodontitis, implant loss and peri-implantitis. A meta-analysis. Clinical Oral Implants Research, 26(4), e8-e16. 10.1111/clr.12319

Silva, N., Abusleme, L., Bravo, D., Dutzan, N., Garcia-Sesnich, J., Vernal, R., \& Gamonal, J. (2015). Host response mechanisms in periodontal diseases. Journal of Applied Oral Science, 23(3), 329-355. 10.1590/1678-775720140259

Tonetti, M. S., Greenwell, H., \& Kornman, K. S. (2018). Staging and grading of periodontitis: Framework and proposal of a new classification and case definition. Journal of Clinical Periodontology, 45, S149-S161. 10.1111/jcpe.12945

Ussher, J. E., Bilton, M., Attwod, E., Shadwell, J., Richardson, R., de Lara, C., \& Willberg, C. B. (2013). CD161++CD8+T cells, including the MAIT cell subset, are specifically activated by IL-12+IL-18 in a TCR-independent manner. European Journal of Immunology, 44(1), 195-203. 10.1002/eji.201343509

Yoshikai, Y., \& Nishimura, H. (2000). The role of interleukin 15 in mounting an immune response against microbial infections. Microbes and Infection, 2(4), 381-389. 10.1016/s1286-4579(00)00329-4

Zhang, X., Wang, Q., Yan, X., Shan, Y., Xing, L., Li, M., \& Lai, W. (2020). Immune landscape of periodontitis unveils alterations of infiltrating immunocytes and molecular networks-aggregating into an interactive web-tool for periodontitis related immune analysis and visualization. Journal of Translational Medicine, 18(1). 10.1186/s12967-020-02616-1

Zhuang, L., Fulton, R. J., Rettman, P., Sayan, A. E., Coad, J., Al-Shamkhani, A., \& Khakoo, S. I. (2018). Activity of IL-12/15/18 primed natural killer cells against hepatocellular carcinoma. Hepatology International, 13, 75-83. 10.1007/s12072-018-9909-3 